\title{
Faro de Mesa Roldán
}

Mario Sanz Cruz | farero, escritor y agitador cultural

URL de la contribución <www.iaph.es/revistaph/index.php/revistaph/article/view/4005>

\section{RESUMEN}

El faro de Mesa Roldán, inaugurado en 1863, es uno de los más importantes de Almería y se encuentra en una privilegiada situación, a más de 210 metros sobre el nivel del mar, dentro del Parque Natural Cabo de Gata-Níjar. Un edificio histórico que, con diferentes modificaciones, se mantiene erguido, realizando su trabajo de señalización marítima. Actualmente es el único, en Almería, que sigue habitado por su farero y contiene un pequeño museo que pretende mantener viva la memoria de los faros y los fareros, en una época en que se extinguen rápidamente, ante la presión de las nuevas tecnologías y la tiranía de los recortes.

\section{Palabras clave}

Almería | Campo de Níjar | Caracterización | Carboneras | Faros (Edificios) | Farero | Lámparas | Linterna (Utensilios) | Óptica | Torrero | 


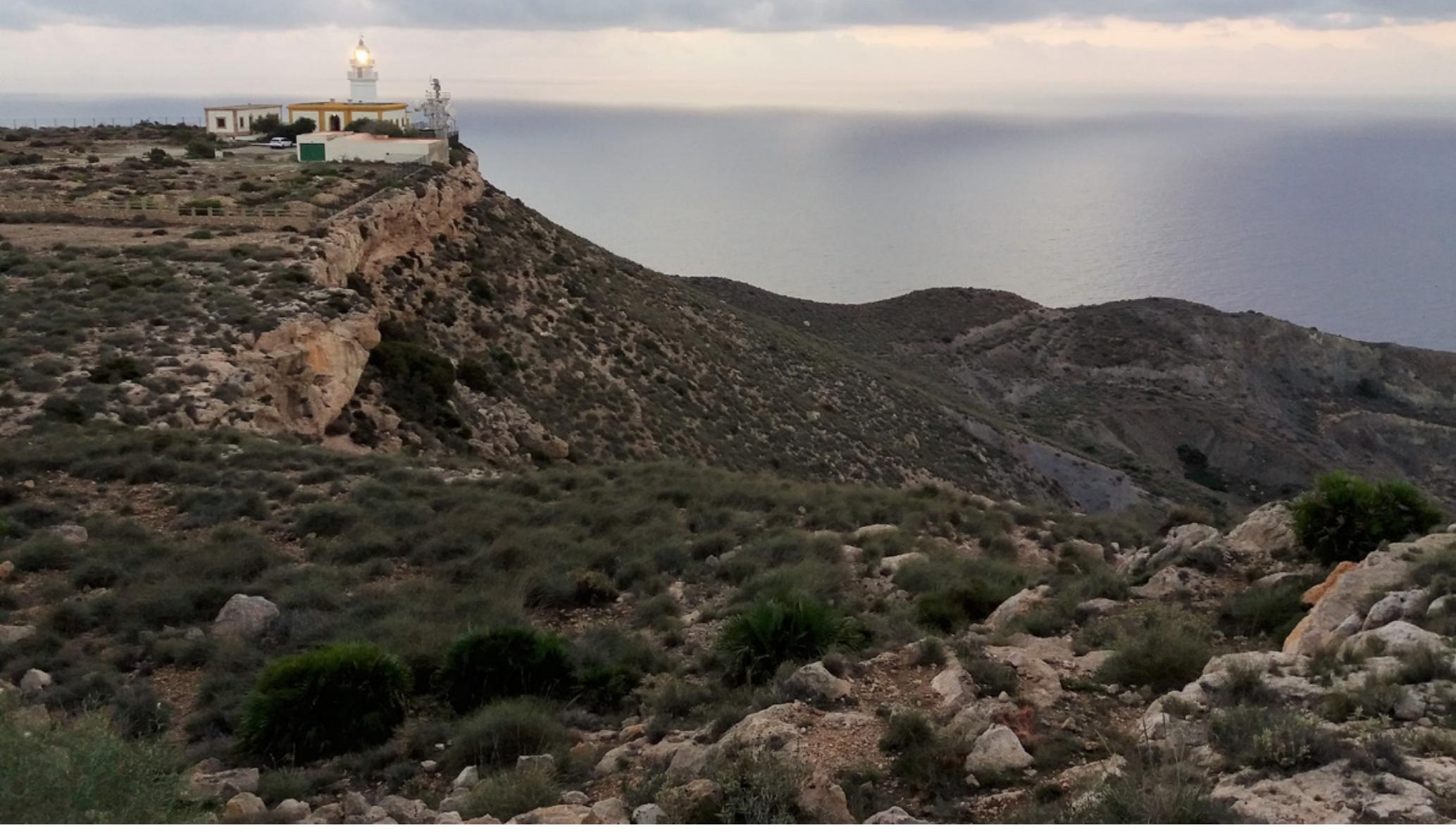

Faro de Mesa Roldán panorámica | foto Mario Sanz Cruz es autor de todas las imágenes mientras no se indique lo contrario 


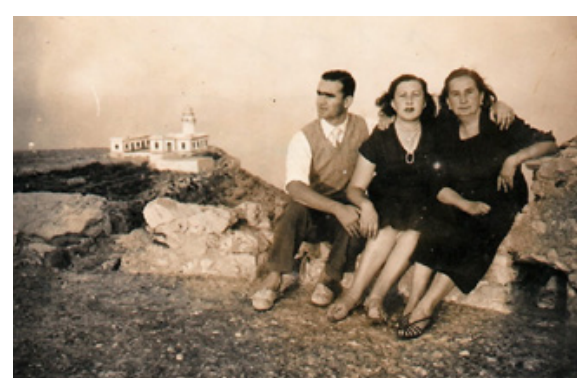

El farero Ramón Pérez con su mujer y su suegra, en 1953 | foto José Pérez Suárez
"Ya no quiero vivir sino en el Faro de esta Mesa.

Cansado de vivir en diminuto, hoy siento la mar de otra manera."

Pedro Guerrero Ruiz

El faro de Mesa de Roldán está situado en la cima de una meseta caliza, a 210 metros de altura sobre el mar, lo que le hace tener una de las panorámicas más espectaculares del Mediterráneo. Situado a 8 kilómetros de Carboneras y a 4 de Agua Amarga, ha sido el faro más aislado de la costa almeriense, ya que su altitud dificultaba tanto el transporte por mar como por tierra.

En la misma meseta hay una torre vigía, sobre la que, antes de la creación del faro y hasta su inauguración, Antonio José Belmonte encendía una hoguera todas las noches.

El faro se construyó por efecto de la Real Orden de 18 de diciembre de 1857. El proyecto fue realizado por el ingeniero Antonio Molina, en 1861, con un presupuesto de 198.034,62 reales. El edificio original era de planta cuadrada, con torre octogonal de 10,5 m de altura, adosada en el lado del mar, coronada por una linterna decagonal. El aparato óptico, de tercer orden gran modelo, tenía una parte fija y un juego de lentes giratorias, accionadas por máquina de relojería de gravedad. Todo de la casa francesa Henry Lepaute. La lámpara Degrand se alimentaba con aceite de oliva.

Durante las obras se incorporaron el torrero primero Eustasio Page y el tercero Francisco Manresa. En esas fechas, Carboneras era un pueblo con enormes carencias, que los torreros calificaban de "pueblo infeliz en supremo grado".

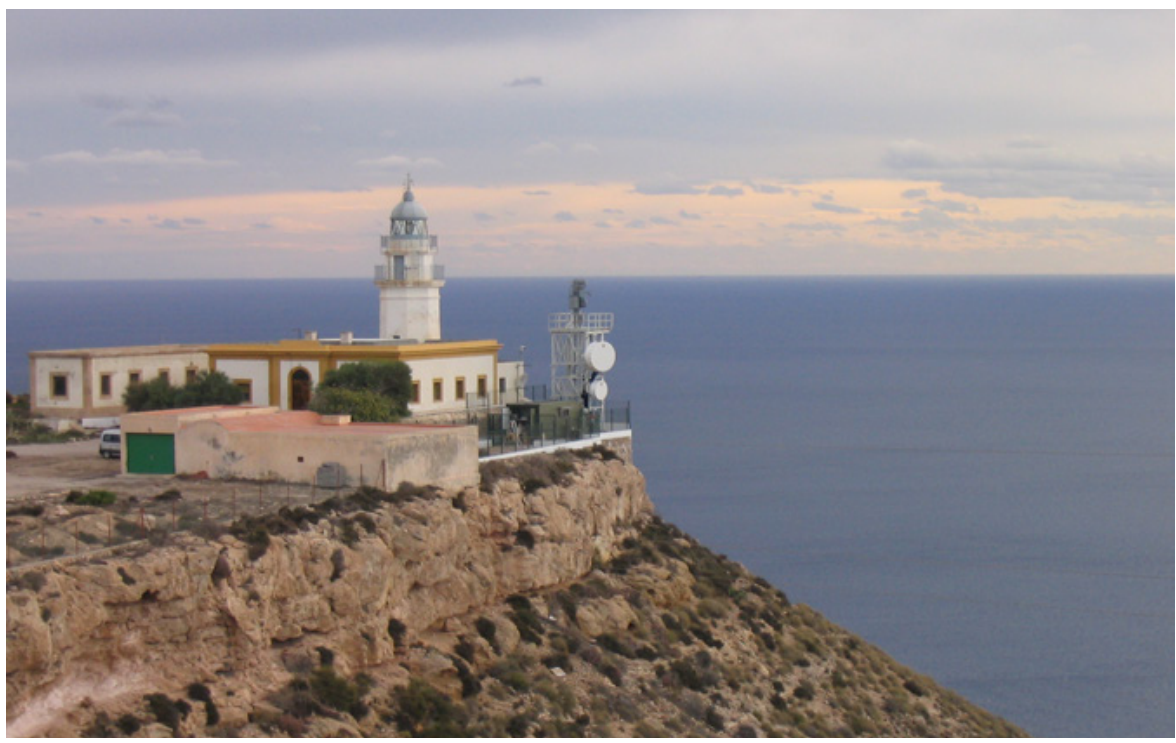




\section{PARO DE IA ITESA DE ROLDAN}
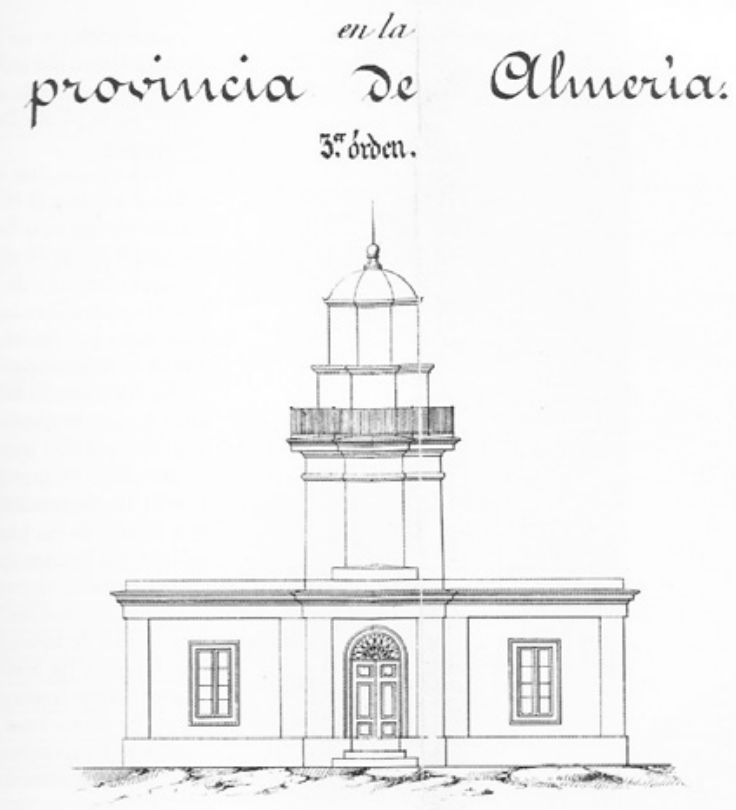

Alzado faro de Mesa Roldán | fuente SANZ CRUZ, 2007: 199

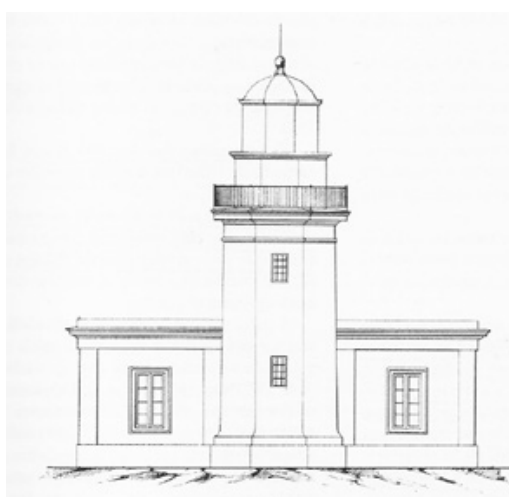

Vista desde el lado del mar, del faro de Mesa Roldán | fuente SANZ CRUZ, 2007: 199

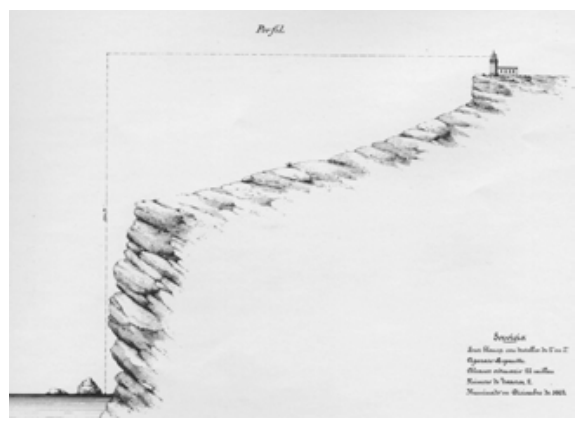

Perfil situación del faro de Mesa Roldán | fuente SANZ CRUZ, 2007: 208

Eustasio Page estuvo veintitrés años en este faro, haciendo la vida imposible a sus compañeros hasta que logró meter, como torrero auxiliar, a su hijastro Baldomero Emilio Alcaraz. Este primer torrero encargado, todo un carácter, fue el azote de los demás fareros, pero nos ha legado una gran cantidad de documentación con floridas descripciones, que ilustran cómo fue la vida en el faro.

El faro se inauguró el 31 de diciembre de 1863, dando una apariencia de destellos cada dos minutos, con alcance de 22 millas. A partir de 1882, se sustituye la lámpara de aceite por un mechero Dotty de dos mechas alimentado por parafina de Escocia y, en 1901, pasó a consumir petróleo. En 1923 se sustituyó la parte giratoria de la óptica, por cuatro lentes verticales alternadas con pantallas, montadas sobre un flotador de mercurio, accionado por máquina de relojería, y se montó una lámpara de vapor de petróleo a presión Chance; quedando con grupos de 4 destellos y alcance de 22 millas. Paralelamente se construyó el edificio exterior como almacén y vivienda de suplencias.

El 3 de mayo de 1931, el torrero Simón Fuentes, que había entrado diez años antes y estuvo veintiuno de servicio en este faro, escribía en el diario de servicio: "Media hora poco más o menos antes de encender y cuando me 


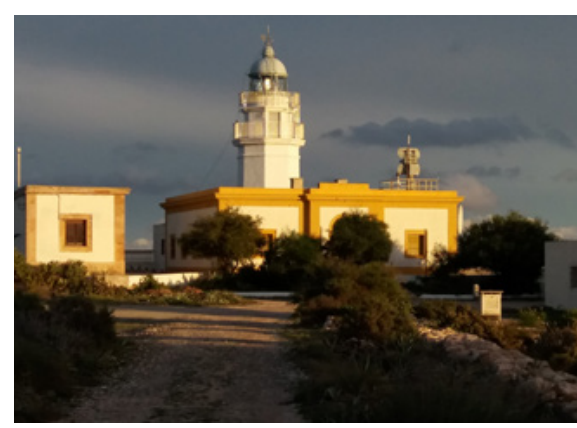

Faro de Mesa Roldán

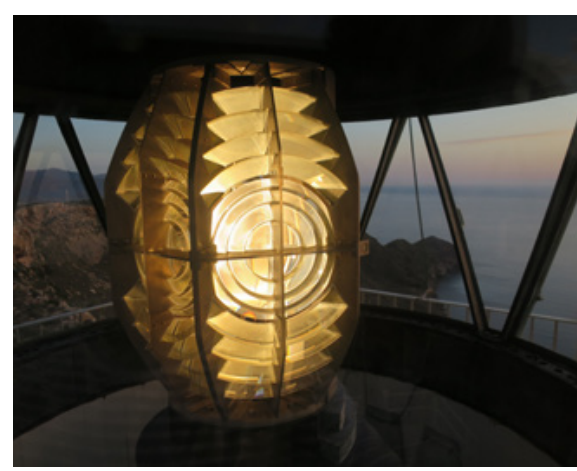

Linterna y óptica del faro de Mesa Roldán encontraba preparándole la comida a una caballería menor que tengo de mi propiedad, se me presentó el torrero agregado Antonio Fernández Pérez y sin mediar palabra alguna me disparó tres tiros con una pistola que afortunadamente no hizo blanco, viéndome precisado a correr y abandonar el faro para poder salvar la vida." El mismo día, Antonio Fernández ponía "sin novedad" en el diario. No sabemos qué habría puesto si llega a hacer blanco en su compañero. Al día siguiente, Simón volvía al faro acompañado por la Guardia Civil, que detuvo al agresor.

En este faro fueron frecuentes las caídas de rayos y las tempestades, pero la más rara nos la relata el mismo Simón Fuentes, el 2 de febrero de 1934: "Durante toda la noche los cristales de la linterna que dan a la parte norte han estado completamente cubiertos de nieve y aunque a intervalos y con exposición de la vida hemos procurado baldearla de la cornisa y de los cristales, no deja de haber sido un gran inconveniente para los efectos de los navegantes, por la magnitud del sector que ha estado sin alumbrar."

Iniciada la Guerra Civil, el 1 de noviembre de 1936 se apagaba la luz por orden del jefe de la Base naval. Una semana después se encendía por orden del ingeniero. El 13 de septiembre de 1937 volvía a apagarse por orden del jefe de Defensa de costas y los fareros quedaban en funciones de observación y vigilancia, hasta el final de la guerra.

En 1972, el faro se electrificaba con una lámpara de incandescencia de $3.000 \mathrm{~W}$ y dos grupos Ruston de reserva. La característica quedaba con grupos de 4 destellos cada 30 segundos.

En la vida del faro, influyeron mucho las cercanas canteras, que dieron grandes sustos y problemas a los torreros entre 1978 y 1989, rompiendo cristales, parando la óptica, desplomando el techo del pasillo, etc.; todo debido a las voladuras.

En 1985 se instalaba una linterna auxiliar Tideland, y en 1986 se realizaban obras de ampliación del edificio, vallado, acondicionamiento general, y automatización del faro con cambio de linterna, óptica, sistema de iluminación y giro, todo de la Maquinista Valenciana, quedando la característica con grupos de 4 destellos cada 20 segundos y alcance de 23 millas, que es la actual. En 1996 se cambiaron las lámparas de incandescencia de 1.500 W por halógenas de $1.000 \mathrm{~W}$ y menor tamaño.

Mi incorporación a este faro, en 1992, supuso un enorme cambio de vida. Mi mujer, Amalia, y yo veníamos de Madrid, y cambiamos la ciudad por un inmenso horizonte de mar. Entonces no podía sospechar que yo sería el último farero de Mesa Roldán. En 1993 el Cuerpo de Técnicos Mecánico de Señales Marítimas se declaraba a extinguir, quedando los fareros en exce- 
dencia, trabajando en las Autoridades Portuarias de cada zona, en mi caso en la de Almería-Motril.

Mi vida en el faro ha sido tranquila, pero no exenta de anécdotas y sobresaltos. Hemos sufrido temporales que han arrancado vallas y árboles, han inundado el edificio, y rayos han quemado los cuadros del faro. Hemos asistido a persecuciones de alijos de droga, y la búsqueda de un buzo de la Guardia Civil que, desgraciadamente, se ahogó mientras sacaba uno de estos alijos. Han aterrizado helicópteros en Mesa Roldán, ha emergido un submarino en la Punta de Los Muertos y hemos visto incendiarse un pesquero. Han pasado barcos de todas clases y han volado, muy cerca, todo tipo de aviones. Hemos visto flamencos, garzas, ballenas, delfines y calderones. Hemos recibido visitas de colegios, universidades, comandos de la Legión, periodistas de diarios, radios y televisiones, rodajes de documentales, cortos, series y películas; y hemos disfrutado mucho de tan privilegiado lugar.

La tranquilidad del faro me ha servido para escribir un poco de todo: poesía, relatos, artículos y libros de diferentes temáticas; destacando el tema faros. Como último farero de Mesa Roldán y uno de los últimos de España, trato de conservar la memoria de los faros y fareros, en mis escritos y en un museo que, desde 2010, muestra mi colección particular, en una de las alas del faro, y puede ser visitado con cita previa. Actualmente, Mesa Roldán es un faro vivo, que abre sus puertas a las actividades culturales y a los admiradores de los faros, para que todo el mundo sepa que los faros son mucho más que señales marítimas, y que merecen ser conservados y cuidados.

\section{Nota}

El autor basa este trabajo en dos obras suyas publicadas: Faro de Mesa Roldán. Apuntes para una historia (Almería: Diputación de Almería, Instituto de Estudios Almerienses, 2003) y Faros de Almería. Mucho más que señales marítimas (Almería: Diputación de Almería, Instituto de Estudios Almerienses, 2007). 